\title{
Survey Research in Domestic Violence Facilities: Challenges and Best Practices
}

David W Moore*

Tags: qualitative research, violence against women

\section{Survey Practice}

Vol. 6, Issue 3, 2013

\begin{abstract}
In the United States, there are approximately 2,000 domestic violence facilities, ranging from short-term shelters to longer-term transitional housing facilities providing a safe haven for women and their children fleeing life-threatening violence. Survey researchers interested in working with populations resident in domestic violence facilities may find that a number of social and legal factors complicate their ability to do so, including legal restrictions, trauma-informed trust issues, social services fatigue, facility culture, and restricted access to records. This article offers a brief overview of these issues and offers research-based best practices for overcoming them in survey research.
\end{abstract}

In the United States, there are approximately 2,000 domestic violence facilities united via their membership in state coalitions against domestic violence and the National Network to End Domestic Violence (NNEDV) (Iyengar and Sabik 2009). These facilities range from short-term shelters to long-term transitional housing facilities providing a safe haven for women and their children fleeing life-threatening violence. In its fourth annual "census" of these facilities, the NNEDV determined that, in a 24-hour period, 48,350 individuals used their services, including crisis telephone calls, counseling, and shelter (NNEDV 2009). Those interested in carrying out survey research with populations resident in domestic violence facilities may find that a number of social and legal factors complicate their ability to do so. These challenges include legal restrictions, trauma-informed trust issues, social services fatigue, facility culture, and restricted access to records. This article offers a brief overview of these issues and offers research-based best practices for overcoming them in survey research.

A number of federal and state laws work in tandem with domestic violence facility staff to protect the confidentiality of residents, who may be in hiding and fearing for their lives. These legal protections, while very important, can prevent survey researchers from accessing administrative records, speaking directly to residents, or carrying out research at facilities. Survey researchers can assure facility staff that they also have legal obligations to protect residents' confidentiality as a result of their responsibilities to an Institutional Review 
Board and professional norms that safeguard vulnerable research participants. These legal concerns about confidentiality are further compounded by residents' past trauma and the emotionally charged environment of everyday life in domestic violence facilities.

There are pervasive trust issues among staff and residents at domestic violence facilities. In the course of my research in domestic violence facilities, I have encountered residents who described the inability of police and courts to protect them from their abusers as a major source of mistrust. I also observed a number of resident children who were visibly afraid of uniformed police officers, who they associated with the removal of their father from the family unit. Survey researchers should endeavor to make all of their interactions with facility staff members meaningful and singular out of respect for the fraught nature of everyday life at these facilities. The trauma-informed culture of mistrust at many facilities also applies to federally funded studies, as staff and residents may have concerns that such studies could potentially disclose confidential information to government agencies, including the undocumented status of some residents.

Most domestic violence facilities feature an environment of near-constant activity, which leaves staff members with very little time to concentrate on any single task for very long, let alone accommodating the needs of survey researchers. The pervasive state of anxiety characterizing these facilities stems from multiple factors, including, understaffing due to budgetary limitations, the need to complete the minutiae of various state and federal grants, often with very little notice or ability to prepare, the high frequency of sudden crises in residents' daily lives, and, above all, acute staff awareness that all residents have been the target of life-threatening violence and that their abusers could arrive at the facility at any time and place everyone in danger. This last concern necessitates policies that either forbids visitors entirely or ensure that no visitors have a criminal record of violent offenses, as there is an omnipresent threat of violence against residents or staff at all facilities. Survey researchers will have a greater likelihood of successfully engaging staff and residents if they have some previous experience with domestic violence-related work or, better still, express willingness to undergo the volunteer training most facilities offer on a monthly basis or semiannual basis.

Staff and residents at domestic violence facilities may be less inclined to engage with survey researchers due to social services fatigue, a condition brought on by the constant need for residents and staff to complete forms and answer questions as a condition of service provision. The environment at most domestic violence facilities features a constant flow of social service providers, as well as residents traveling to offices that refuse to accept forms via email or fax. Most residents (and the staff who assist them) find it exhausting to keep up with all of the various social service agency forms that need to be submitted, inspections that need to be endured or undertaken in order to have 
basic accommodations for themselves and their children, all while maintaining or searching for low wage work and caring for several dependent children. For many women, participating in survey research has a low priority in the hierarchy of urgent tasks that need to be completed in order to ensure their family's survival. Once permission has been obtained from staff members to carry out the survey research, researchers are advised to stress the "real world" implications of their study, including the possibility that the research could positively influence domestic violence-related law and public policy.

Survey researchers must also be cognizant of the fact that domestic violence facilities may differ significantly in philosophy, rules, and attitudes. Guiding philosophies vary considerably, from a feminist empowerment model stressing residents' rights to individual decision-making to a more regimented, authoritarian structure that focuses on the need to monitor residents' decision-making processes. Facility directors who advocate a more laissez-faire and less interventionist approach to managing residents are typically old enough to remember the late 1970s, when violence against women was still an activist issue addressed largely by the feminist movement. This is quite different from some of their younger contemporaries, who began their careers already accustomed to the professionalization of social services and increased government involvement in and regulation of what was formerly an exclusively activist domain. Survey researchers can adjust their requests for access to the facility in accordance with these organizational philosophies, which are often evident in facility promotional materials, such as websites, or in key phrases used by staff.

Facilities that employ a feminist empowerment model will, for instance, embrace a philosophy of, to use an oft-repeated phrase from a facility I worked in, "staff do not know what is best for clients, because they don't have to deal with the consequences." On the opposite side of the spectrum, the philosophy of more highly structured facilities assume that residents need help and guidance because their lives are in such an unsettled state. In such facilities, breathalyzers, drug tests, and other punitive regulations are common and can make residents feel suspect or even criminalized. Survey researchers should be aware that staff and resident responses to research requests and resulting data quality will likely differ significantly based upon resident perceptions of their levels of autonomy. Hence, survey researchers would be wise to inform themselves about the organizational environment in which they wish to carry out research prior to making a research request.

Although domestic violence occurs across the socioeconomic spectrum, one thing that domestic violence-oriented facilities typically have in common is the fact that they often house a particular socioeconomic demographic. Residents at such facilities are generally poor, less formally educated and have fewer resources to draw upon than their more privileged peers, who can access social networks, savings and credit if they are faced with violence in the home. Indeed, 
the vast majority of domestic violence facility residents I have encountered in my research rely upon low wage work or Temporary Assistance to Needy Families benefits to support themselves and their children, making them almost entirely dependent upon the facility. If survey researchers are able to offer a non-coercive financial incentive for residents to participate in the research, it might help to improve their chances of receiving access to the facility.

A final potential concern for survey researchers stems from the restricted access to accurate administrative records at domestic violence facilities. Many women in such facilities are from other towns, cities, counties, states, or countries, as there is an elaborate network of both clandestine and publically known domestic violence facilities across North America that function like an "underground railroad" to hide women and protect them and their children from abusers. Residents' origins are not always accurately reflected in administrative records because directors of such facilities are dependent upon county or state funding and thus need to demonstrate that they receive only a limited number of nonresidents. It is not inconceivable that facility directors might "over-count" the number of local residents in order to receive more money from local donors and government. Survey researchers should be mindful of this when requesting information.

Survey research in domestic violence facilities presents a number of challenges, many of which can be overcome using sensitivity and some of the strategies outlined here.

\section{REFERENCES}

Iyengar, R. and L. Sabik. 2009. The dangerous shortage of domestic violence services. Health Affairs 28(6): 1052-1065.

National Network to End Domestic Violence (NNEDV). 2009. Domestic violence counts 2009: a 24 hour census of domestic violence shelters and services. National Network to End Domestic Violence, Washington, DC. 